\title{
Traffic Stream Relationships of Two-Lane Highways: A Case of Akure-Ondo Road in Southwest Nigeria
}

\author{
Ipindola O. O. ${ }^{1}$, Falana J. N. ${ }^{2}$ \\ ${ }^{1}$ Civil Engineering Technology Department, Federal Polytechnic Ile-Oluji \\ olajideipindola@yahoo.com \\ ${ }^{2}$ Civil Engineering Technology Department, Federal Polytechnic Ile-Oluji \\ justinaokwueze@yahoo.com
}

\begin{abstract}
In the design and planning process of highway infrastructure, speed-flow-density relationships are useful tools for predicting the roadway capacity, determining adequate level-of-service of traffic flow and travel time for a given roadway. The speed-flow-density relationships currently used for transportation studies in Nigeria is derived from the Highway Capacity Manual, which does not reflect the true traffic situation on twolane roads in Nigeria. Developing cost effective tools for describing these relationships in the context of a developing country like Nigeria is imperative.

The aim of this study was to develop models to describe the relationship between traffic flow, speed and density on Akure-Ondo two-lane highway in southwest Nigeria. Moving observer technique was employed to collect traffic stream data over a stretch of $5 \mathrm{~km}$ on the study segment during periods of uniform flow on weekdays. To describe the traffic stream relationships, two approaches namely: related and nonrelated traffic stream models were developed. The nonrelated traffic stream models gave inaccurate relationships while the related traffic stream modelling approach performed well at describing speed-flow, flow-density and flow-speed relationships with $R^{2}$ values $0.62,0.75$, and 0.80 respectively. The relationships developed from related traffic stream models estimated maximum flow on the study segment as $330 \mathrm{veh} / \mathrm{h}$ at an optimum density of $4.44 \mathrm{veh} / \mathrm{km}$. The speed at maximum flow was estimated as $74.5 \mathrm{~km} / \mathrm{h}$, while the free flow speed was estimated as $149.027 \mathrm{~km} / \mathrm{h}$.
\end{abstract}

Keywords-Capacity, Moving observer technique, Traffic stream models, Two-lane highway.

\section{INTRODUCTION}

Speed-flow-density relationships are the most useful tools in the highway design and planning process. They are useful in predicting the road capacity, in determining the adequate level-of-service of traffic flow and in determining travel time for a given roadway [1] Improving the level of service of highway facilities contributes positively to socio economic development especially in a developing country like Nigeria where the major means of transportation is road.

Traffic flow can generally be described in terms of three parameters: mean speed $(v)$, traffic flow rate $(q)$, and the traffic density $(k)[2 ; 3]$. The three parameters are related to each other by the equilibrium relationship:

$q=v k$ (1)

The speed and the density describe the quality of service experienced by the traffic stream while the flow rate measures the quantity of the stream and the demand on the highway facility [4; 5].Flow, speed and density are the major macroscopic traffic stream characteristics. Flow rate is a variable that quantifies demand. It is the number of vehicles that desire to use a given facility during a specific time period. Speed is an important measure of effectiveness defining levels of service for many types of facilities. Density is a critical parameter for uninterrupted flow facilities because it characterizes the quality of traffic operations [6]. The relationships between these three variables are called traffic stream models. Macroscopic stream models represent how the behavior of one parameter of traffic flow changes with respect to another.

Over the years researchers have developed various methods such as tally count, pneumatic tube, point detector, radar, video camera and ultrasonic for measuring these basic traffic flow parameters [7; 8].Recently, there has been increased interest in moving observer method of collecting traffic stream data which has the advantage of recording the flow, travel time and mean speed simultaneously. This technique is explained further in section 2.2 .

The operational characteristics of flow in a traffic stream are described by two flow regimes namely: free-flow and congested flow [9]. The highway facility under study is operating under a free-flow condition and the effect of small and local disturbances in the temporal and spatial patterns of the traffic stream are insignificant. 
Development of mathematical relationships among the primary elements of a traffic stream: flow, speed and density; helps traffic engineers in planning, designing, and evaluating the effectiveness of implementing traffic engineering measures on a highway system[10]. Over the years, several researchers in the field of transportation have developed models to explore these relationships. Greenshields assumes that under uninterrupted flow conditions, speed and density are linearly related[11].

The general model connecting speed and density which is a linear model proposed by Greenshields is of the form:

$V=V f-\frac{V f}{K j} k$

Where: $\mathrm{V}$ is the space mean speed; $V f$ is space mean speed for free flow conditions; $k$ is density and $K j$ is jam density.

Greenberg assumes that speed-density relationship is logarithmic rather than linear while Underwood assumes that speed-density relationship is exponential [12]. The relationship between speed and density using the moving observer technique for data collection in Dhaka, Bangladesh was explored by [13]. Three classical speeddensity models: greenshields, Greenberg and underwood were fitted in the graphical representation of speeddensity relationship and the corresponding parameters determined using statistical software. Sensitivity analysis and statistical significance tests of the models were compared with the moving observer data. The relationship between flow, speed and density for urban roads in Fallujah city in Baghdad was studied by [14].Reference [15] developed single regime models that describe the relationships between; speed, density and flow rate parameters of uninterrupted urban flow on elevated roads in Cairo, Egypt. Data on traffic characteristics such as flow rate, speed, density and headway were collected using video camera on $60 \mathrm{~m}$ long section.Among the various methods for collecting traffic data, moving observer technique as described by [16] is of interest in this study.

In a developing country like Nigeria where demographic and economic factors have placed an unprecedented demand on highway facilities, it is essential to understand the relationship between traffic stream parameters. The problems of poor lane discipline, heterogeneous traffic, high percentage of heavy vehicles and safety issues particularly on two-lane highways justifies the modelling of traffic stream parameters. A high percentage of the Nigerian road network is made up of two lane highways linking major cities such as the Akure - Ondo road under study. Many of these highways are under the management of local and state governments with inadequate economic resources. It is therefore important to develop cost effective tools to explore the relationship between traffic stream parameters on two lane highways in Nigeria in other to improve the performances of these facilities. Whereas $[17 ; 18]$ have modelled operating speed and headway characteristics of two-lane highways in Nigeria, little has been documented on modelling the relationship between traffic stream parameters and this makes this study important.

In this study, a two lane highway linking Akure (Ondo state capital) and Ondo town in southwest Nigeria was selected for study. Moving observer technique was employed in the collection of traffic flow and mean speed data from which the density was calculated using the fundamental traffic flow relationship (1). The field data was analyzed and traffic stream models developed to explore the relationship between flow, speed and density. Boundary conditions (maximum flow rate, optimum density, optimum speed and free flow speeds) were estimated from the models developed. The performance of the models developed was evaluated using Coefficient of determination $\mathrm{R}^{2}$.

\section{METHODOLOGY}

The data collection procedure and preparation for analys is is explained in this section. Traffic volume, travel time and average speed data were collected simultaneously using the moving observer technique. The collected data was processed and made suitable for statistical analys is.

\subsection{Selection of Study Section}

The first step in the collection of traffic data was the selection of road for study. Akure-Ondo two-lane highway (Fig. 1) was selected for this study because of its importance to the socioeconomic development of Ondo state. Additionally, the road segment has an appreciable traffic volume operating under free flow conditions and suitable for traffic flow studies. The second step was the selection of study section from which traffic data were collected. A $5 \mathrm{~km}$ section between Bolorunduro junction and Owena market located at longitude $7^{0} 16^{\prime}$ and $7^{0} 19^{\prime} \mathrm{E}$ and latitude $4^{0} 96^{\prime}$ and $5^{0} 02^{\prime} \mathrm{Nwas}$ selected for further studies.

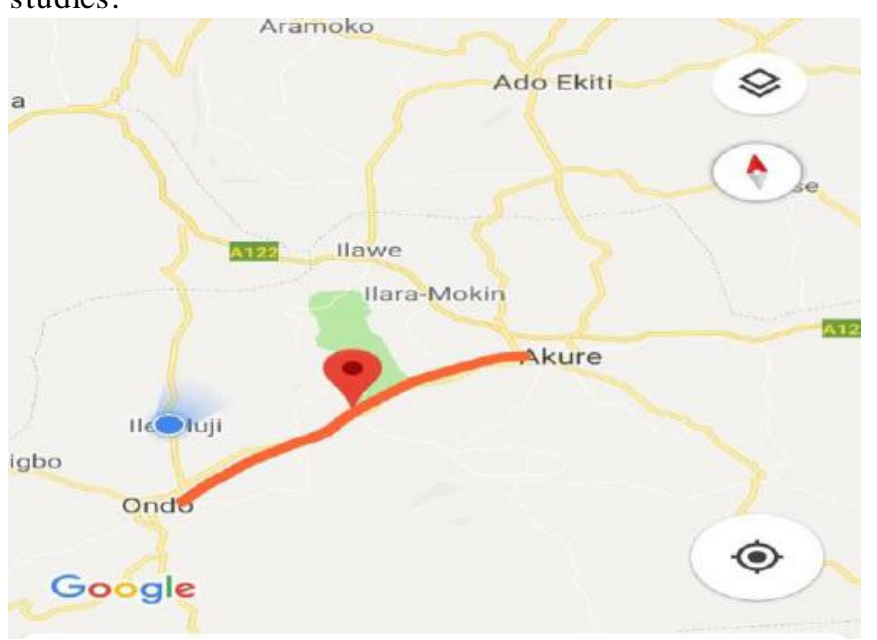

Fig.1: Location of Study section on Google Map. 


\subsection{Data Collection}

Moving observer technique as described in the Manual of Transportation Engineering Studies [16] was employed for the collection of traffic flow rate, mean speed and travel time.

For a complete description of traffic stream modeling, one would require flow, speed and density. Obtaining these parameters simultaneously is a difficult task if we use separate techniques. Since we have a fundamental equation of traffic flow, which gives the flow as the product of density and space mean speed, if we knew any two parameters, the third can be computed. Moving car or moving observer method of traffic stream measurement has been developed to provide simultaneous measurement of traffic stream variables. This method was first proposed by [19] as a method of estimating the average flow and travel time of traffic moving in one or the other direction on a freeway segment. The method was founded upon the measurements made by the moving observer in a test vehicle embedded in the traffic. The observer travelled in a test car in the direction of the stream considered with the flow while counting the number of vehicles overtaking and the number of vehicles passed. Travel is also made against the flow in the other direction, to record the number of opposing vehicles faced in the opposite direction during the trip. In both travel directions, the trip time of the test car is recorded. Additionally, the length of the road segment is known. These measurements are then used in calculating the speed-flow relationship for the road segment in the direction of interest. Several runs are conducted to increase the accuracy.

The following information for each run was recorded by the observer in the test vehicle.

1. The number of vehicles overtaking the test vehicle.

2. The number of vehicles overtaken by test vehicle.

3. The number of vehicles encountered, while travelling opposite to the direction of interest.

4. The segment length and trip time of the observer in both directions, with and against traffic flow.

The advantages of using the moving observer technique as stated by [19] are as follows:

1. The observer can collect the information on speed and flow simultaneously.

2. The observer can measure travel time along the length of the road segment and also the flow rate and the average speed of vehicles.

3. The amount of man power and hours needed to attain a high level of accuracy is less for the moving observer method compared to other methods, thus making it less expensive.
4. Vehicles can be grouped and flow rate can be estimated for each group.

The section chosen for this study is located on Akure Ondo two lane highway located in Ondo state in southwest Nigeria. The geometric features of the study section are consistent with high traffic flow to increase confidence in the result.

Traffic data were collected in different times of the day and different days of the week to represent all conditions of traffic flow from Monday 5th, 2018 to Sunday 11th, 2018.The weather condition was good and the pavement dry. A segment of $5 \mathrm{~km}$ was used for data collection. A total of twenty runs were performed on the test segment in order to achieve a proportional error of 0.05 [20]. In the test car, real time traffic events were captured by the observer using a video recorder over the entire period of study in other to minimize human error.The recorded traffic datawere saved on a computer system for further processing and analysis.

\subsection{Data Processing}

The collected data from the video recorder were gathered in excel, and then processed to obtain the three macroscopic traffic stream parameters: flow rate, mean speed and density.

To calculate the hourly flow rate, the following equation was used:

$q=\frac{M w+M a}{T w+T a}$

Where:

$\mathrm{q}$ is flow rate, $\mathrm{Mw}$ is difference between vehicles overtaking observer vehicle and vehicles overtaken by observer, $\mathrm{Ma}$ is vehicles moving against the traffic flow opposite the direction of interest, Tw is travel time to traverse the study segment with traffic, and Tais travel time to traverse the study segment against traffic.

Mean speed was calculated using the following equation:

$u=\frac{L}{\left[T w-\frac{M a}{q}\right]}$

Where:

$\mathrm{U}$ is mean speed and $\mathrm{L}$ is the length of study segment (km),

Density was calculated using the fundamental traffic flow relationship (1).

The descriptive statistics of the fundamental traffic flow parameters are presented in Table 1.

2.4 Data Analysis

Statistical analysis was performed on the traffic flow parameters to describe the observed patterns. The relationship between flow rate, mean speed and density was developed using two approaches namely: developing nonrelated traffic stream models and developing related traffic stream models as described in the following section. 
2.4.1 Development of Nonrelated Traffic Stream Models

The relationship between the traffic stream parameters flow, speed and density was developed based on the data collected by the moving observer method using the best fit curve technique in SPSS statistical software. The basic relation (5) between the three variables was neglected as described by[11]. The developed relationships are presented in section 4.4 of this document.

2.4.2 Development of Related Traffic Stream Models

To describe the exact relationship between the traffic parameters, Greenshield's macroscopic stream model was applied [11]. He assumed a linear speed-density relationship to derive his model (5). Once the relationship between speed and density was established, the relationship with flow could be derived.

2.4.2.1 Speed -Density Relationship

$V=V f-\frac{V f}{K j} k$

Where: $V$ is the mean speed at density $K, V f$ is the free flow speed and $K j$ is the jam density.

2.4.2.2 Flow-Density Relationship

Flow-density relationship is derived as described below:

$V=V f-\frac{V f}{K j} k$

$$
q=v k
$$

Where $\mathrm{Q}$ is the traffic flow

By substitution;

$$
q=\left[V f-\frac{V f}{K j} k\right] k
$$

By simplification;

$$
q=\left[V f k-\frac{V f}{K j} k\right] k^{2}
$$

\subsubsection{Speed - Flow Relationship}

The relationship between speed and flow was derived as described below;

From (5);

$$
K=K j-\left[\frac{K j}{V f}\right] k
$$

By substituting for $\mathrm{K}$ in (6);

$$
q=V K j-\left[\frac{K j}{V f}\right] V^{2}
$$

\section{RESULTS AND DISCUSSION}

\subsection{Traffic Stream Parameters}

The descriptive statistics of the traffic stream parameters is presented in Table 1.The maximum flow rate recorded on the study segment was $329 \mathrm{veh} / \mathrm{h}$ while the minimum was $283 \mathrm{veh} / \mathrm{h}$. this infers that on average, 7000 vehicles traverse case study daily. The mean speed is 94.65 $\mathrm{km} / \mathrm{hth}$ is is in tandem with [17]. The posted speed limit on the study segment is $100 \mathrm{~km} / \mathrm{h}$. This may mean that majority of the drivers are travelling within the speed limit. There is a need to conduct a spot speed study in other to examine the accuracy of the moving observer technique. The maximum density observed on the study segment is $3.2 \mathrm{veh} / \mathrm{km}$.

Table.1: Descriptive Statistics of Traffic Stream Parameters

\begin{tabular}{|l|r|r|r|r|r|r|}
\hline & $\mathrm{N}$ & Minimum & Maximum & \multicolumn{1}{c|}{ Mean } & Std. Deviation & Variance \\
\hline speed & 20 & 88.00 & 104.00 & 94.6500 & 4.33195 & 18.766 \\
density & 20 & 2.80 & 3.61 & 3.2395 & .22589 & .051 \\
flow & 20 & 283.00 & 329.00 & 305.9000 & 11.86725 & 140.832 \\
Valid N (list-wise) & 20 & & & & & \\
\hline
\end{tabular}

\subsection{Traffic Composition}

The composition of traffic stream in both directions along the study segment is presented in(Fig.2). Passenger car makes $69 \%$ of the total traffic followed by motorcycle/tricycle. The percentage of motorcycle/tricycle is high because there are quite a number of farm settlements adjoining the study segment in which majority of them use motorcycle as a means of transportation to their non-motorable farms. The impact of land use on the traffic stream could be a subject of future research. The heterogeneity of the traffic stream further justifies the need to develop traffic stream relationships suitable for local conditions and not the "one-size-fits-all" approach. The implication of this phenomenon on the traffic flow is outside the scope of this study.

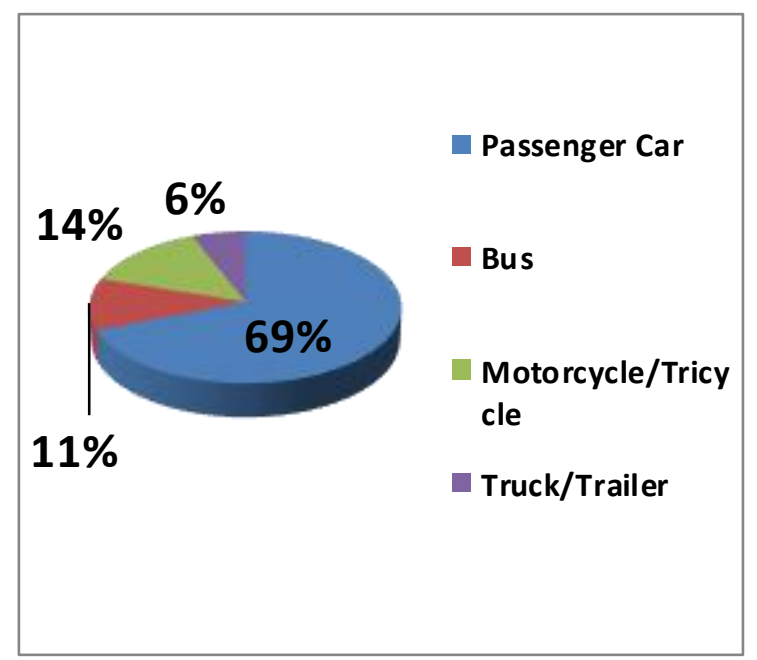

Fig.2: Composition of Vehicles in the Traffic Stream 
Scatter diagrams were plotted between speed-density, speed-flow, and flow-density using the data collected from the study segment (Fig. 3, 4, and 5). It is observed from these charts that the data collected covers a wide range of traffic stream parameters. The linearity of the speed-density relationship chart supports the claims of Greenshield [11]. The scatter diagram of speed-density relationship indicates that when density becomes zero, speed approaches free flow speed. The ideal relationship between flow and density and flow-speed are parabolic in shape [11] though this is not clearly seen in the scatter plot possibly because the chart forms a part of the whole curve(Fig. 4 and 5).

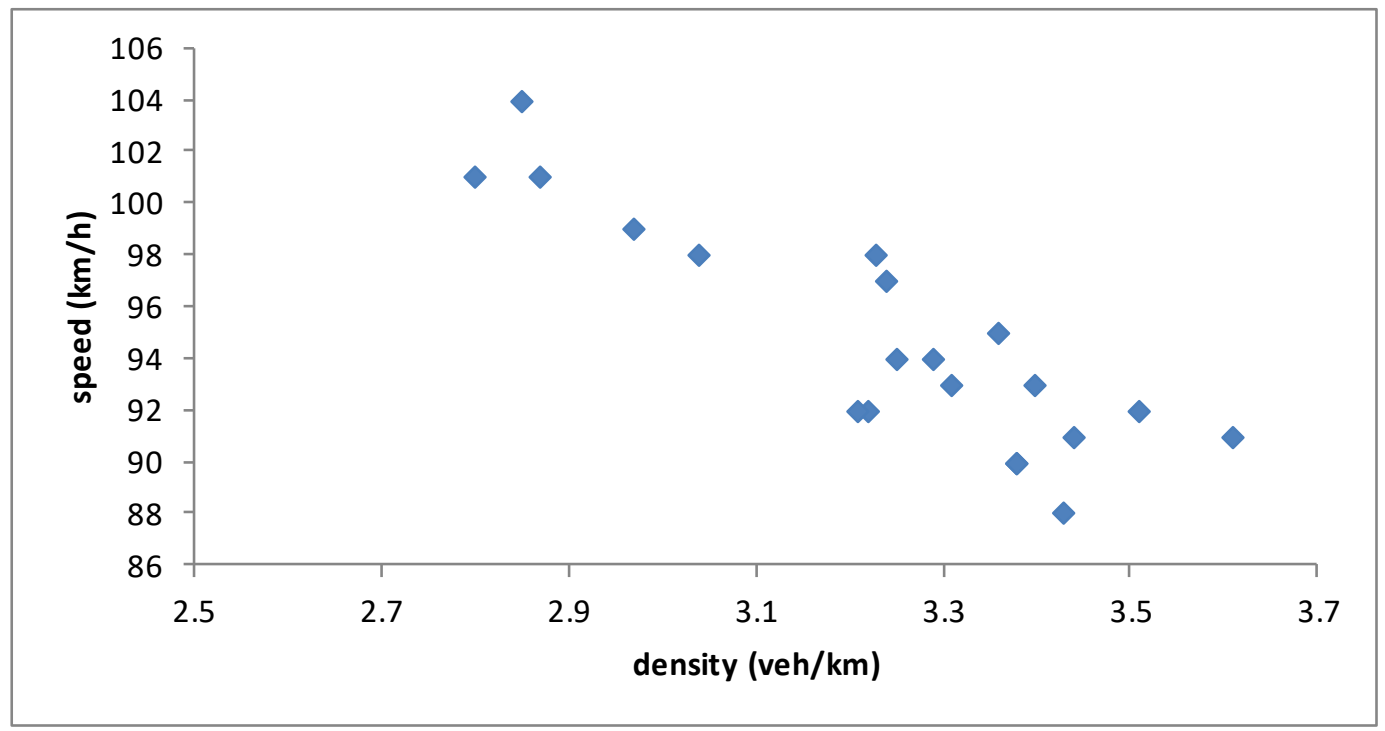

Fig.3: Speed - Density Relationship

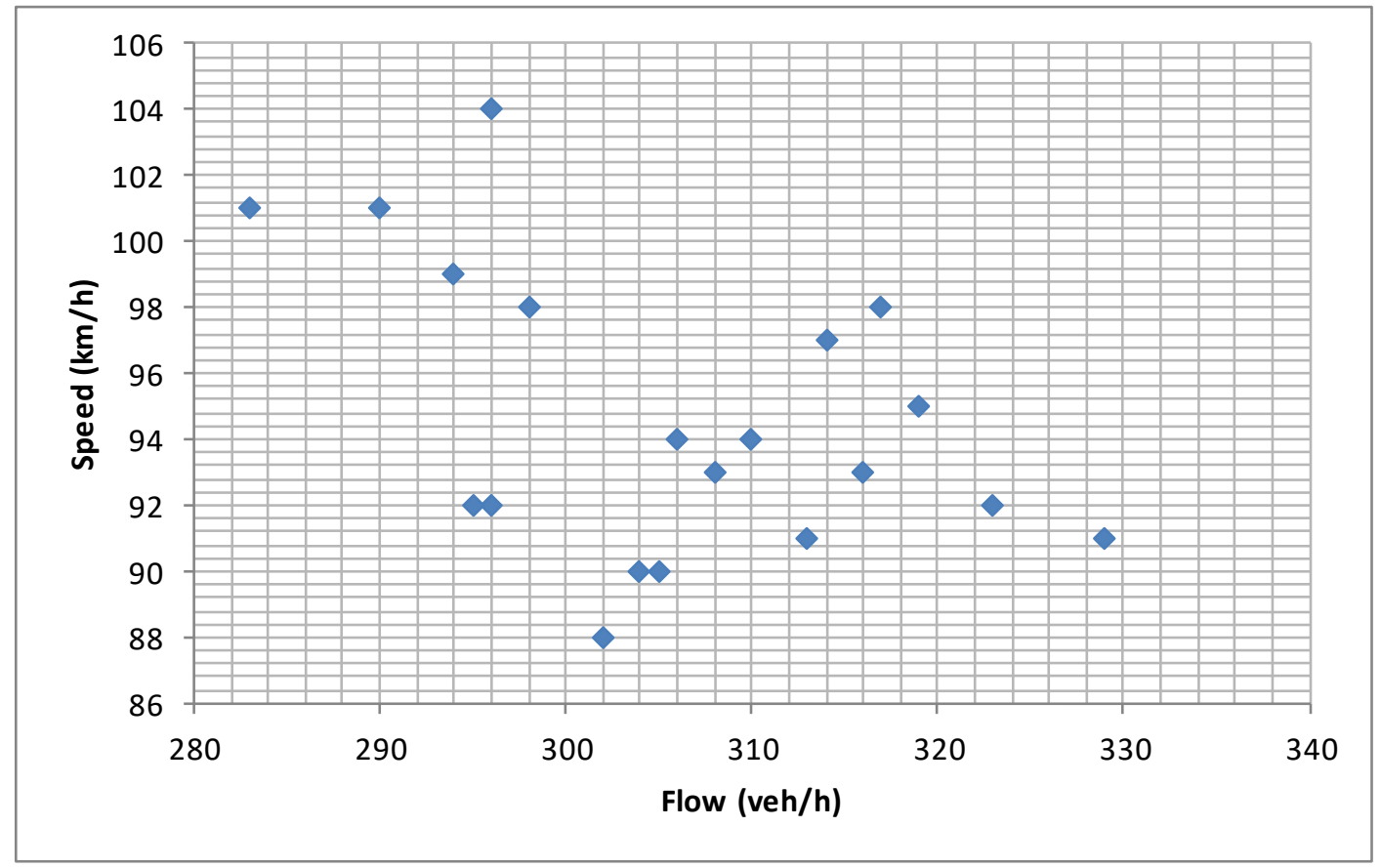

Fig.4: Speed - Flow Relationship 


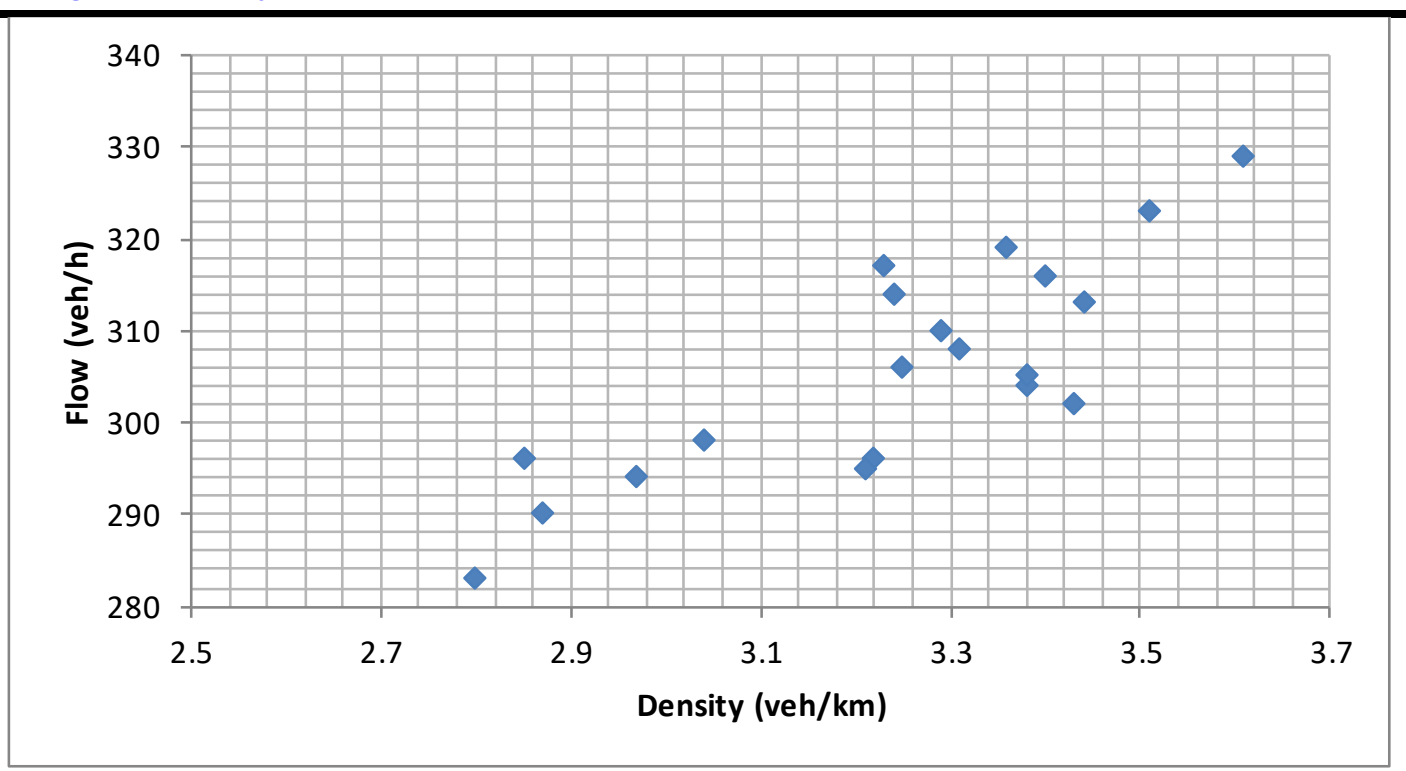

Fig. 5: Flow - Density Relationship

3.4

\section{Model Development}

Best fit curve technique was used to develop the relationship between the traffic stream variables; flow, speed and density based on the collected data by neglecting the fundamental relationships between the three variables[11].The developed relationships are presented in (8),(9) and (10).

\section{Speed - Density Relationship}

$u=149.027-16.786 k$

Flow - Density Relationship

$q=376.791-90.442 k+21.066 k^{2}$

Flow - Speed Relationship

$q=-1457.22+38.084 u-0.205 u^{2}(10)$

This relationship is inaccurate because at density or speed equal to zero, flow rate is not equal to zero. In addition to this, the estimated values are different for the same inputs in the above equations. These short comings necessitate the development of related traffic stream models.

\subsubsection{Related Traffic Stream Models}

The first step in developing related traffic stream models was to develop the best fit speed-density relationship (11),then flow-density and flow-speed models were developed from this relationshipas presented in (12 and 13).Equation 11 validates the claim of [11] that speeddensity relationship is linear under free flow conditions.Using the relationships developed in $(11,12$, and 13), the maximum flow of the two-lane road under study was estimated as $330 \mathrm{veh} / \mathrm{h}$. This result is very close to the maximum flow rate of $329 \mathrm{veh} / \mathrm{h}$ recorded during field survey. The density at the maximum flow rate was estimated as $4.44 \mathrm{veh} / \mathrm{km}$. This implies that when the road under study is operating at capacity there are 4.44 vehicles on a kilometer of road section and they are travelling at a speed of $74.51 \mathrm{~km} / \mathrm{h}$. The free flow

\subsubsection{Nonrelated Traffic Stream Models}

speed was estimated as $149.027 \mathrm{~km} / \mathrm{h}$. This implies that when the density tends towards zero a vehicle can travel as high as $149.027 \mathrm{~km} / \mathrm{h}$ on the road segment under study, though the posted speed limit is $100 \mathrm{~km} / \mathrm{h}$.

Speed - Density model

$u=149.027-16.786 k$ at $k<4.44 v e h / k m(11)$

Flow - Density model

$u=149.027 k-16.786 k^{2}$ at $k<4.44 v e h / k m(12)$

Flow - Speed model

$q=8.74 u-0.058 u^{2}$ at $u>74.51 \mathrm{~km} / \mathrm{h}(13)$

The developed models are applicable for free flow speed equal to $149.027 \mathrm{~km} / \mathrm{h}$ or less.

3.5 Model Performance

In this study, coefficient of determination $\left(\mathrm{R}^{2}\right)$ was employed to evaluate the performance of the related traffic stream models developed. The developed models performed well at describing the relationship between traffic stream parameters. This result is similar to [21].

Table.2: Summary of Related Traffic Stream Model

\begin{tabular}{ll}
\multicolumn{2}{c}{ Performance } \\
\hline Relationship & $\mathbf{R}^{\mathbf{2}}$ \\
\hline Speed-Density & 0.80 \\
Flow-Density & 0.75 \\
Flow-Speed & 0.62 \\
\hline
\end{tabular}

\section{CONCLUSION}

Development of mathematical relationships among the primary elements of a traffic stream: flow, speed and density; helps traffic engineers in planning, designing, and evaluating the effectiveness of implementing traffic engineering measures on a highway system. The macroscopic relationships between traffic stream parameters: flow, speed and densityof a two-lane highway 
in southwest Nigeria have been investigated. The application of moving observer technique in collection of traffic flow parameters was found satisfactory, but there is a need to compare its accuracy with other methods like manual counts and spot speed. The related traffic stream models developed in this study performed well at describing the relationship between flow-speed, flowdensity and speed-density. These models can be found useful by policy makers, researchers and transportation engineers. Future research can consider investigating the impact of heterogeneity and land use on traffic stream characteristics.

\section{REFERENCES}

[1] Twagirimana, J. 2013 "Establishing and Applying Speed-Flow Relationships for Traffic on Rural TwoLane Two-Way Highways in the Western Cape" Masters of Engineering Thesis in the Faculty of Engineering at Stellenbosch University.

[2] Payne, H. J. 1979 "A Macroscopic Simulation Model of Freeway Traffic" Transportation Research Record722:68-77.

[3] Wu, N. 2002 "A New Approach for Modelling of Fundamental Diagrams" Transportation Research Part A, 36: 867-884.

[4] Salter, R. J. and Hounsell, N. B. 1996 "Highway Traffic Analysis and Design" Macmillan: London.

[5] May, A. D. 2001 "Introduction to Traffic Flow Theory in C. A. O'Flaherty (Ed.)" Transport Planning and Traffic Engineering, Bristol: Butterworth-Heinemann.

[6] TRB, "Highway Capacity Manual 2000" National Research Council Washington D.C.

[7] May, A. D., Athol, P., Parker, W., and Rudden, J. B. 1963 "Development and Evaluation of Congress Street Expressway Pilot Detection System" Highway Research Record 21: 48-70.

[8] Athol, P. 1965 "Interdependence of Certain Operational Characteristics within a Moving Traffic Stream" Highway Research Record 72: 58-87.

[9] Colombo, R. M. 2002 "Hyperbolic Phase Transitions in Traffic Flow" Society for Industrial and Applied Mathematical 63.2: 708-721.

[10] Nicholas J. G., Lester A. H., "Traffic and Highway Engineering" University of Virginia, 2003.

[11] May, A. D. 1990"Traffic Flow Fundamentals, Traffic Engineering Handbook", Prentice-Hall, Englewood Cliffs, New Jersey.

[12] Wang, H., Li, J., Chen Q. Y., and Ni, D. 2009 "Speed-Density Relationship: Deterministic to Stochastic" Submitted to TRB $88^{\text {th }}$ Annual Meeting, Washington D.C.
[13] Barua, S., Das, A., and Hossain, M. J. 2015 "Estimation of Traffic Density to Compare SpeedDensity Models with Moving Observer Data" International Journal of Research in Engineering and Technology, 4(8) pg 471-474.

[14] Alkabaisi, M. I., Abbas, R. A. 2011 "Speed Flow Density Models Prediction for Urban Roadways in Fallujah City" Anbar Journal for Engineering Sciences, 4 (1), 1-16.

[15] El-Adawi, M. 1993 "Development of a Traffic Stream Model for Elevated Urban Roads in Cairo" Master Thesis, Cairo University Giza, Egypt.

[16] Robertson, H. D. and Findley, D. J. 2010 "Manual of Transportation Engineering Studies, $2^{\text {nd }}$ Edition" Institute of Transportation Engineering.

[17] Ipindola, O. O. 2018 "Modelling of $85^{\text {th }}$ Percentile Speed at Selected Mid-Curves on Ondo-Ife TwoLane Rural Highway in Southwestern Nigeria" International Journal of Innovative Research and Advanced Studies (IJIRAS), 5(11), 158-160.

[18] Akintayo, F. O. and Agbede, O. A. 2009 "Headway Distribution Modelling of Free-flowing Traffic on Two-lane Single Carriage Ways in Ibadan" Proceedings of the $1^{\text {st }}$ International Conference on the Role of Engineering and Technology in Achieving Vision 20:2020 - RETAV 2009 (17-19 Nov., 2009), ObafemiAwolowo University, Ile-Ife, Nigeria: $240-246$.

[19] Wardrop, J. G. and Charlesworth, G. 1954 "Method of Estimating Speed and Flow of Traffic from a Moving Vehicle" Proceedings of the Institution of Civil Engineers, 3, 158-169.

[20] Mulligan, A. and Nicholson, A. 2010 "Uncertainty in traffic flow estimation using the moving-observer method" university of Canterbury, New Zealand.

[21] El Sherief, M. M., Ramadan, M. I., and Ibrahim, A. M. 2016 "Development of Traffic Stream Characteristics Models for Intercity Roads in Egypt" Alexandria Engineering Journal 55, 2765-2770. 